\title{
Needleless Melt-Electrospinning of Polypropylene Nanofibres
}

\author{
Jian Fang, ${ }^{1}$ Li Zhang, ${ }^{1}$ David Sutton, ${ }^{2}$ Xungai Wang, ${ }^{1}$ and Tong Lin ${ }^{1}$ \\ ${ }^{1}$ Australian Future Fibres Research and Innovation Centre, Deakin University, Geelong, VIC 3216, Australia \\ ${ }^{2}$ LyondellBasell Australia Pty Ltd., Corio, VIC 3214, Australia
}

Correspondence should be addressed to Tong Lin, tongl@deakin.edu.au

Received 13 December 2011; Accepted 4 March 2012

Academic Editor: Gajanan S. Bhat

Copyright () 2012 Jian Fang et al. This is an open access article distributed under the Creative Commons Attribution License, which permits unrestricted use, distribution, and reproduction in any medium, provided the original work is properly cited.

\begin{abstract}
Polypropylene (PP) nanofibres have been electrospun from molten PP using a needleless melt-electrospinning setup containing a rotary metal disc spinneret. The influence of the disc spinneret (e.g., disc material and diameter), operating parameters (e.g., applied voltage, spinning distance), and a cationic surfactant on the fibre formation and average fibre diameter were examined. It was shown that the metal material used for making the disc spinneret had a significant effect on the fibre formation. Although the applied voltage had little effect on the fibre diameter, the spinning distance affected the fibre diameter considerably, with shorter spinning distance resulting in finer fibres. When a small amount of cationic surfactant (dodecyl trimethyl ammonium bromide) was added to the PP melt for melt-electrospinning, the fibre diameter was reduced considerably. The finest fibres produced from this system were $400 \pm 290 \mathrm{~nm}$. This novel melt-electrospinning setup may provide a continuous and efficient method to produce PP nanofibres.
\end{abstract}

\section{Introduction}

Electrospinning has been a widely used platform technology for producing polymer nanofibres [1-3]. It allows good control of fibre diameter, morphology, and functionality [46]. The electrospun nanofibres have a high specific surface area and excellent pore interconnectivity. This unique porous structure plus the function from the material itself has made electrospun nanofibre membranes versatile materials with applications in diverse areas [7-11].

Electrospun nanofibres are typically produced from polymer solutions, and organic solvents have to be used in most cases to form homogeneous polymer solutions. Although the use of organic solvents is not a major concern for labscale nanofibre production, the recovery of solvents for largescale nanofibre production would considerably increase the production cost and cause potential environment pollution. The residue of organic solvent in nanofibres may lead to cytotoxicity in cells, which hinders the application of electrospun nanofibres in some biomedical areas. In addition, solution electrospinning is unable to process nonsoluble polymers, such as polypropylene (PP) and polyethylene (PE).

Electrospinning of molten polymer, also known as meltelectrospinning, has been considered an ideal solution to these problems [12]. Since no organic solvents are involved, melt-electrospinning is more ecofriendly and cost efficient when compared to solution electrospinning, and the resultant nanofibres are cytotoxically safe as well.

Although melt-electrospinning was proposed about 30 years ago [13-15], its research has been restricted due to the difficulties in making an effective experimental setup [16-18] and the lack of theoretical studies [19-21]. Meltelectrospinning is more complicated in setup than solution electrospinning because the system needs to operate in an environment of elevated temperature during the spinning process. Therefore the electric heater needs to be insulated from the high voltage DC power to avoid electrical interference. In some studies, this has been achieved by applying the high voltage electrode to the collector instead of the spinneret $[12,17,22]$. By separating the electric heating system from the high voltage power source, the interference can be reduced substantially. In other studies, a $\mathrm{CO}_{2}$ laser has been used as the heating source [23-25]. This highly controlled and localised laser heating can also avoid the thermal degradation of the polymer melt caused by the longterm exposure to heat.

Physically, a polymer in the melt state is much more viscous and has a lower charge density than its solution. 
Consequently, melt-electrospun fibres are often coarser than those electrospun from polymer solutions, typically over 10 microns in diameter $[22,26,27]$. To reduce the viscosity, polymer blends were employed for melt-electrospinning [28, 29], and additives have been proposed but with limited success [30]. Nearly 20 polymers have been subjected to meltelectrospinning to date [31], and the potential applications of melt-electrospun fibres in industrial and biomedical areas have also been demonstrated [32-35].

PP is a thermoplastic polyolefin with excellent mechani$\mathrm{cal} /$ chemical properties. It has been an important industrial material for many applications, especially in the textile industry to make fibres [36]. However, PP is not soluble in common solvents at room temperature, and conventionally PP fibres are produced by a melt-extrusion or melt-blown technique. It remains challenging to prepare PP fibres with diameters on the nanometre scale.

In our previous work, we have developed a needleless solution electrospinning setup which used a rotary metal disc as the spinneret [37]. By loading a polymer solution onto the disc edge and charging it with a high electric DC voltage, a large number of solution jets were generated spontaneously from the disc edge surface. Nanofibres produced in this way were uniform with a much higher productivity than those produced by conventional needle solution electrospinning. This novel setup allowed the mass production of nanofibres for a wide range of applications.

In addition, surfactants have been used as an additive to prevent the formation of fibre beads and to reduce the fibre diameter during solution electrospinning [38]. However, the influence of an ionic additive on the spinning ability of polymer melts and the resultant fibre dimension have not been well studied [30].

In this study, a needleless melt-electrospinning setup employing a disc spinneret was used to electrospin molten PP. The influence of disc spinneret, operating parameters, PP type, and a cationic surfactant on the fibre morphology were also examined. To our knowledge, this is the first paper on needleless melt-electrospinning.

\section{Experimental}

Materials. PP samples (Metocene (Metocene is a trademark owned and used by LyondellBasell family of companies) MF650X and Metocene MF650Y) were kindly provided by Equistar Chemicals, LP (USA) part of the LyondellBasell family of companies with melt flow rates (MFR) of 1200 and $1800 \mathrm{~g} / 10 \mathrm{~min}$, respectively. Dodecyl trimethyl ammonium bromide (DTAB) was purchased from Sigma-Aldrich (Sydney, Australia). All materials were used as received.

Melt-Electrospinning. A purpose-made needleless melt-electrospinning setup was used in this research. A rotating metal disc was used as the fibre generator, which was partially immersed into a polymer melt bath underneath. To maintain the working temperature, both the disc and the melt reservoir were heated by cartridge heaters (HELIOS), which were connected to a temperature controlling system (Variac SRV5, Powertech). A metal collector above the disc was applied with a high voltage to avoid any electrical interference. The fibre generating section of the setup under the collector was electrically grounded and the whole setup was placed in a plastic box, which was filled with Argon.

Before electrospinning, PP pellets were loaded into the preheated melt bath. The disc started to rotate once the pellets were completely molten. When the entire disc rim was covered by the polymer melt, a high voltage was applied to the collector using a power source (Gamma High Voltage, USA) and fibre spinning was initiated.

Characterisation. The temperature profile of the melt-electrospinning setup was obtained from the thermal images taken by an infrared thermography video camera (H2640, NEC, Japan). The morphology of melt-electrospun fibres was examined using a scanning electron microscopy (SEM, Jeol Neoscope). All samples were gold coated (Bal-tec SCD50 sputter coater) and the images were taken at an acceleration voltage of $10 \mathrm{kV}$. The fibre diameter was calculated using an image processing software package (Image Pro-Plus 4.5, Media Cybernetics Co., Santa Clara, CA). The electric fields were calculated using a finite element method (Comsol Multiphysics 3.5a), and the electric field intensity was obtained from the 2D electric field profile using Matlab R2010. Fourier transform infrared spectra (FTIR) were measured on an FTIR spectrometer (Bruker Optics) in attenuated total reflectance (ATR) mode.

\section{Results and Discussion}

Two PP samples Metocene MF650X and Metocene MF650Y were used for this melt-electrospinning study. Both are commercial grades made using metallocene catalysts to achieve a narrow molecular weight distribution and a high degree of resin consistency. Both samples have very high MFR values, giving them low viscosity after melting which is a critical requirement in melt spinning to obtain very fine fibres.

The melt-electrospinning setup is shown in Figure 1. The temperatures of the heaters and disc were controlled accurately in the range from $280^{\circ} \mathrm{C}$ to $360^{\circ} \mathrm{C}$. When the temperature was set at $280^{\circ} \mathrm{C}$, the $\mathrm{PP}$ started to melt. Applying a high voltage led to electrospinning of fibres, however the spinning process was discontinuous because of the high viscosity of the polymer melt. Only when the temperature was increased to around $320^{\circ} \mathrm{C}$ did the electrospinning process become continuous.

During melt-electrospinning, the rotating disc rim was covered uniformly with a thin layer of molten PP, which could smoothly flow back into the melt bath. When the temperature was increased to $360^{\circ} \mathrm{C}$, a large amount of fumes were emitted from the bath and the polymer melt turned a yellowish colour due to PP degradation.

Two discs were used in the initial experiments, the first made of iron and the second made of aluminium. Figure 2 shows the SEM images of the as-spun PP fibres made 


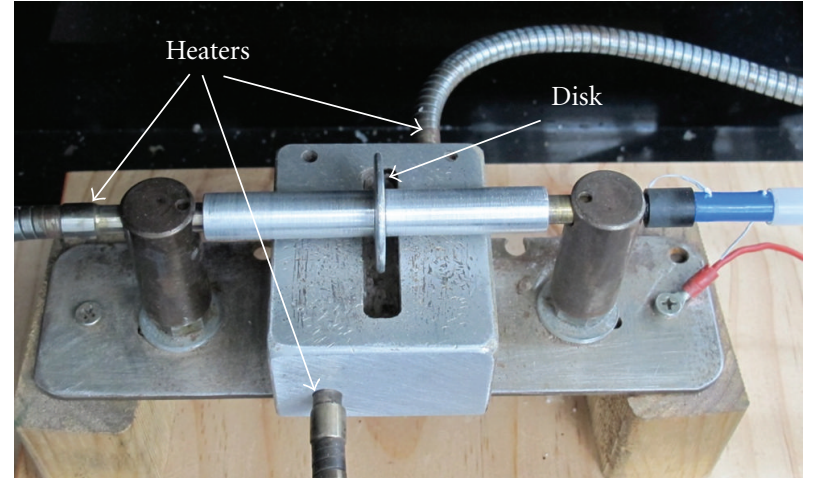

(a)

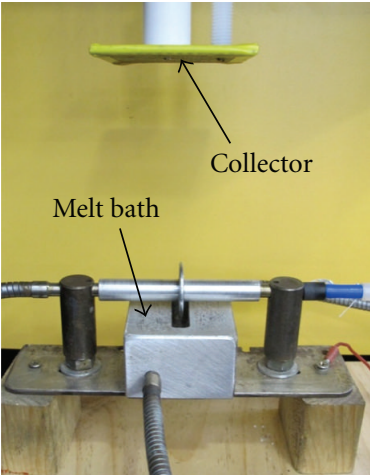

(b)

Figure 1: Photos of the disc melt-electrospinning setup.

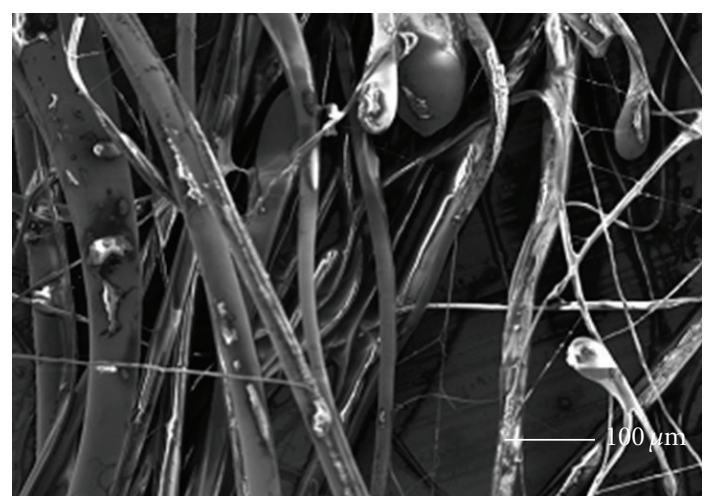

(a)

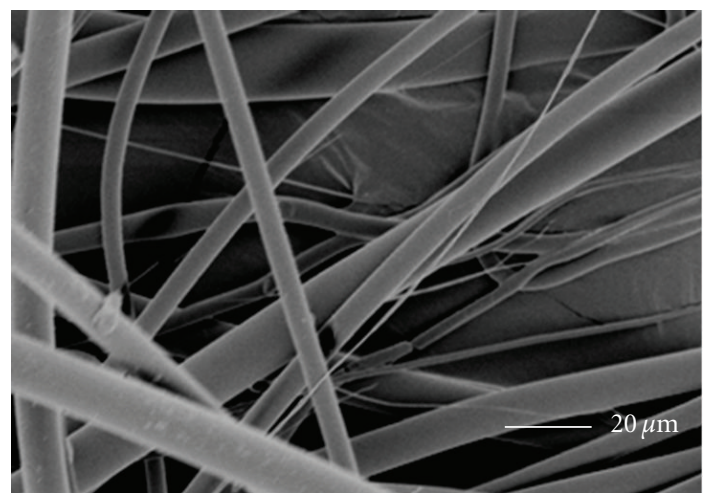

(b)

Figure 2: SEM images of the melt-electrospun PP fibres that were produced using (a) an iron disk and (b) an aluminium disc (MF650Y, applied voltage $=75 \mathrm{kV}$ and collecting distance $=16 \mathrm{~cm}$ ).

using these discs. The iron disc generated fibres having a rough surface and containing some fibre beads, the average diameter of the fibres based on the SEM images was $8.69 \mu \mathrm{m}$. In comparison, smooth fibres were prepared when the aluminium disc was employed and the fibres looked much finer, with an average diameter of $3.31 \mu \mathrm{m}$ and a narrower diameter distribution, (standard deviation of $3.69 \mu \mathrm{m}$ compared with $13.79 \mu \mathrm{m}$ for the fibres prepared with the iron disc). This suggests that the metal material used for making the spinneret strongly influences the fibre diameter and morphology.

Figure 3 shows the temperature profiles of the two setups taken with an infrared thermography video camera. Despite the heater temperatures having been set at the same levels, obvious differences in the temperature profiles were observed on these two thermal images. Three different locations (labelled 1, 2, and 3 on Figure 3(a)) were compared and whilst there was almost no temperature difference at locations 1 and 3 , at location 2 the aluminium disc was nearly red whilst the iron disc was blue. The temperature measured on the aluminium disc edge was $150^{\circ} \mathrm{C}$ whilst it was only $50^{\circ} \mathrm{C}$ at the same point of the iron disc.
It has been established that the heat transfer $(q)$ of a heated object is affected by several factors which are described by [39]

$$
q=\frac{k A d T}{s},
$$

where $k$ is the thermal conductivity of a material, $A$ is the heat transfer area, $d T$ is the temperature difference across the material and $s$ is the transfer distance, which in this case can be considered the disc radius. Hence more heat will be transferred if a material has a higher conductivity. For iron, the thermal conductivity is $31.1 \mathrm{~W} / \mathrm{mK}$ (at $20^{\circ} \mathrm{C}$ ), which is much lower than that of aluminium $(236 \mathrm{~W} / \mathrm{mK})$ at the same temperature. Therefore, more heat was transferred to the edge of the aluminium disc that assisted in compensating for the heat diffusion losses from the disc to the environment.

Disc diameter is another important factor that affects the heating process. Two aluminium discs with different diameters (32 and $40 \mathrm{~mm}$ ) were chosen to investigate this parameter. Before the experiments, the electric field profile was analysed by a finite element method. As shown in Figures 4(a) 


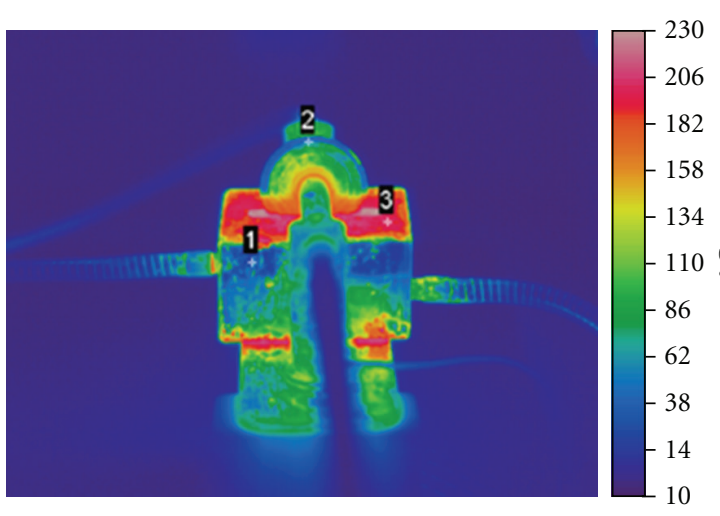

(a)

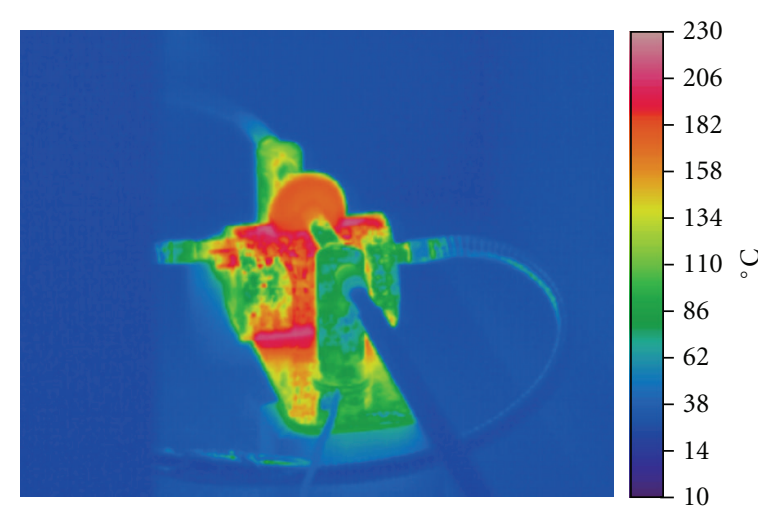

(b)

Figure 3: Temperature profile of the heated iron (a) and aluminium (b) discs.

and 4(b), the highest electric field intensity was concentrated on the four edges of the collector. The electric field isosurface profile (Figures 4(c) and 4(d)) shows a slight difference in the electric field intensity within the spinning space (collecting distances were same, $16 \mathrm{~cm}$ ). The electric field intensity profiles between the top of the discs and the center of the collector (as shown by the red lines in Figures 4(c) and 4(d)) are presented in Figure $4(\mathrm{e})$. The intensity was about $5 \mathrm{kV} / \mathrm{cm}$ on the edge of the $32 \mathrm{~mm}$ diameter disc. This intensity doubled when the disc diameter was increased slightly to $40 \mathrm{~mm}$.

The electric field intensity decreased quickly within a short distance away from the disc edge and then increased to almost the same levels at the collector center. Electric field intensities were also different along the disc edges, and the intensities were highest at the points closest to the collector (Figure 4(f)). At all angles, the electric field intensities on the edge of the $40 \mathrm{~mm}$ diameter disc were almost twice as high as those on the $32 \mathrm{~mm}$ diameter disc.

The two discs also had a large difference in edge temperature, with the smaller diameter disc being almost $50^{\circ} \mathrm{C}$ hotter than the larger disc under the same heating conditions. Due to the lower edge temperature, the larger diameter disc did not produce finer fibres despite the fact that it experienced a higher electric field intensity on the surface. Therefore, the aluminium disc with a diameter of $32 \mathrm{~mm}$ was used in all subsequent experiments.

Two important operating parameters, namely, applied voltage and collecting distance, were examined. The meltspinning process required a very high voltage to produce enough electric field intensity for generating multiple jets, very similar to a solution-based needleless electrospinning process. The minimum voltage required to initiate the spinning process was 50 and $65 \mathrm{kV}$ for the collecting distances of 11 and $16 \mathrm{~cm}$, respectively (Figure 5). These voltages were significantly higher than those used in needle electrospinning for both polymer solutions [40, 41] and melts [12, 27]. The need for a very high applied voltage was attributed to the high viscosity of the PP melt, which made it more difficult to generate melt jets than solution jets.

It was also interesting to note that the voltage could be increased to 75 and $90 \mathrm{kV}$ at the two different spinning distances without any electric discharge being observed. Such high voltages are impossible with needle melt-electrospinning due to the corona discharge. By applying the high voltage onto the collector and electrically grounding the spinneret, melt-electrospinning at a very high voltage was safely achieved whilst keeping the power source and the electric heating system separate.

Most previous research into melt-electrospinning has observed a decreased fibre diameter with increasing applied voltage $[22,29,33]$, normally attributed to the higher stretching force from the increased electric field intensity. However, in this paper the applied voltage had little influence on fibre diameter, although the average fibre diameter appeared to increase slightly when the voltage was higher than $80 \mathrm{kV}$ (spinning distance $=16 \mathrm{~cm}$ ). This is possibly due to fibre drawing without the confinement of a needle, allowing more volume of polymer to be drawn from the molten polymer surface when the electric field is high. Unlike a normal solution electrospinning setup where the flow rate is controlled using a syringe pump, in this melt-electrospinning setup the spinning speed was completely determined by the intensity of the electrostatic force. Hence more polymer melt was stretched out to form fibres at a higher applied voltage, and this could have offset the fibre thinning enhancement under a stronger stretching force.

It was also noted that coarser fibres were always produced at the longer melt-electrospinning distance of $16 \mathrm{~cm}$. One possible explanation is that since the electric field intensity was decreased by almost one-third, this resulted in a dramatic drop in the electrostatic stretching force, and therefore reduced the degree of fibre thinning. The diameter of the finest fibre collected at the melt-electrospinning distance of $11 \mathrm{~cm}$ was $1.73 \pm 1.50 \mu \mathrm{m}$, and this was increased to $3.63 \pm$ $2.77 \mu \mathrm{m}$ when the distance was widened to $16 \mathrm{~cm}$. Therefore the finest fibres had an average diameter of $1.73 \mu \mathrm{m}$, which was still much coarser than those usually obtained from a polymer solution electrospinning process.

Figure 6 shows the relationship between fibre diameter and the DTAB concentration. Most of the PP/DTAB composite fibres were finer than those prepared using pure PP, except for a few exceptions when the DTAB concentration 


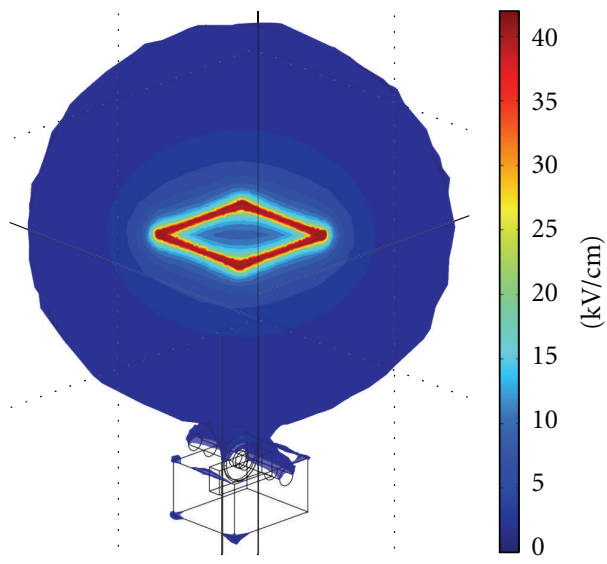

(a)

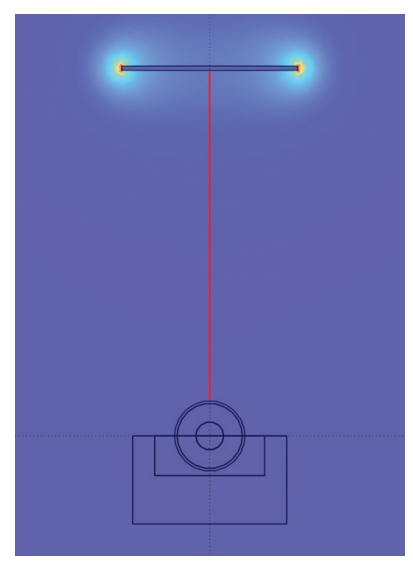

(c)

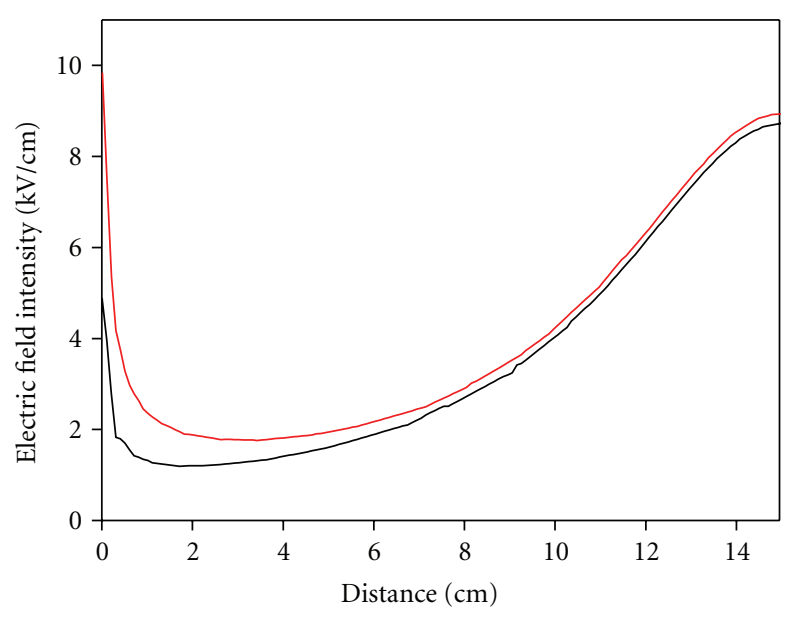

- $32 \mathrm{~mm}$ $40 \mathrm{~mm}$

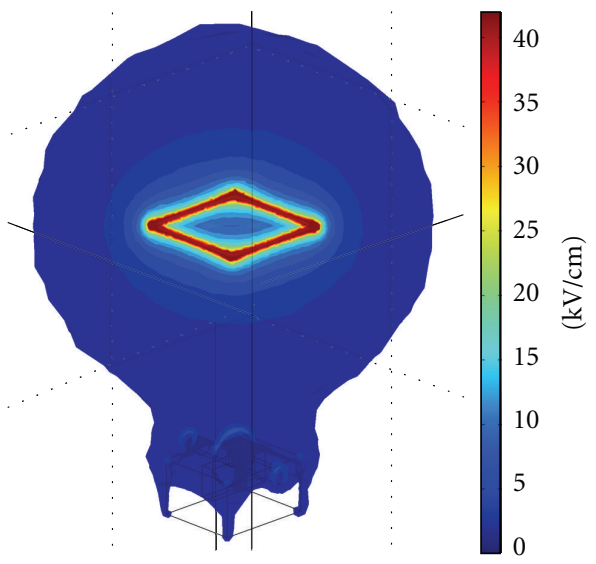

(b)

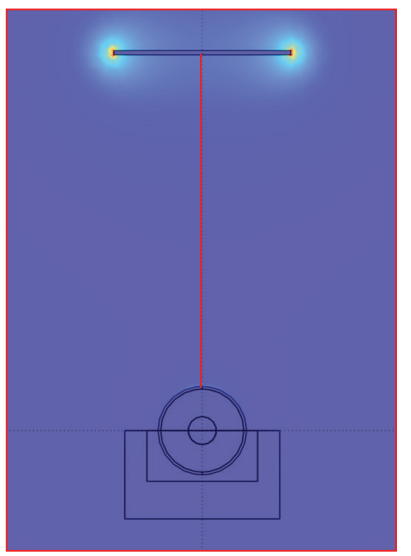

(d)

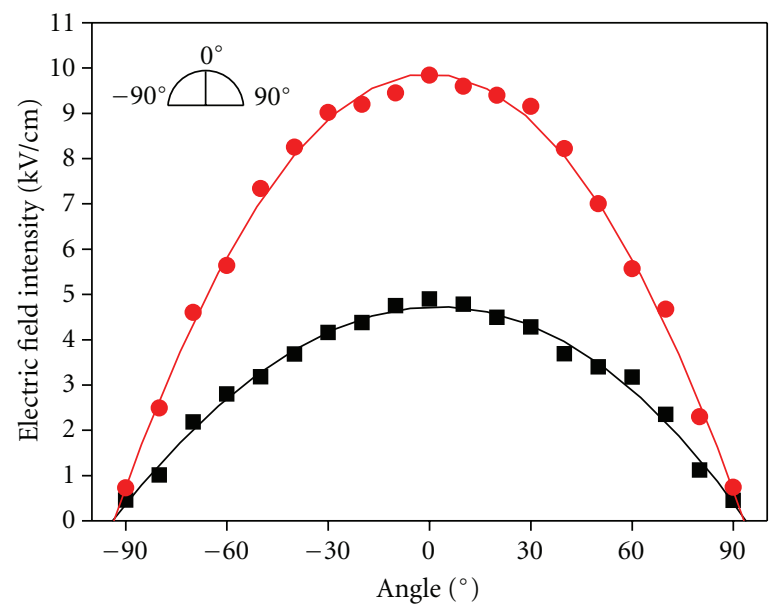

- $32 \mathrm{~mm}$

- $40 \mathrm{~mm}$

(e)

(f)

Figure 4: (a, b) Electric field intensity profile of the needleless melt-electrospinning setup using a disc with the diameter of (a) 32 mm and (b) $40 \mathrm{~mm}$; (c, d) electric field isosurface of the profiles; (e) electric field intensity profile from the top of the disc to the centre of the collector; (f) electric field intensity profile along the disc edges (Applied voltage $=60 \mathrm{kV}$; collecting distance $=16 \mathrm{~cm}$ ). 


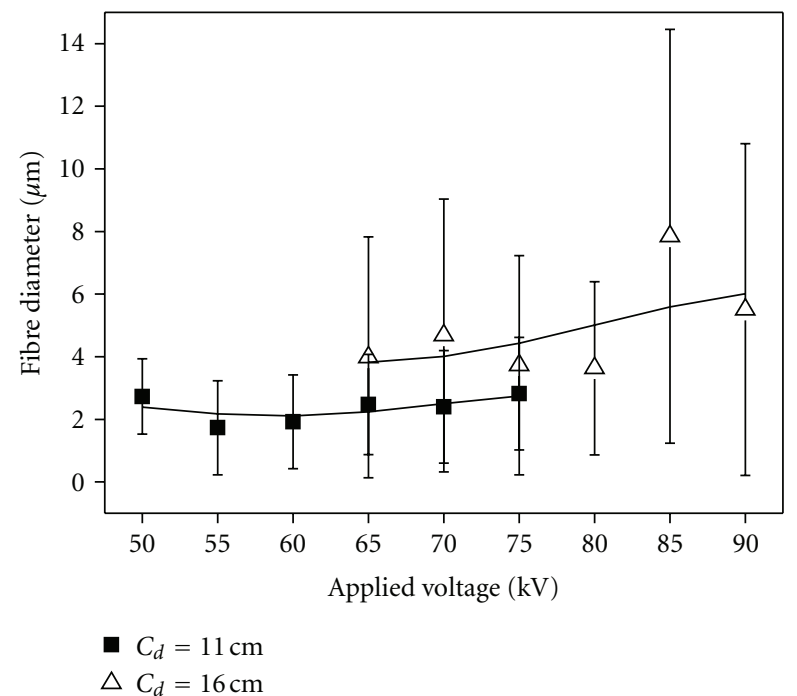

FIGURE 5: Relationship between fibre diameter and the applied voltage at two different collecting distances (MF650Y).

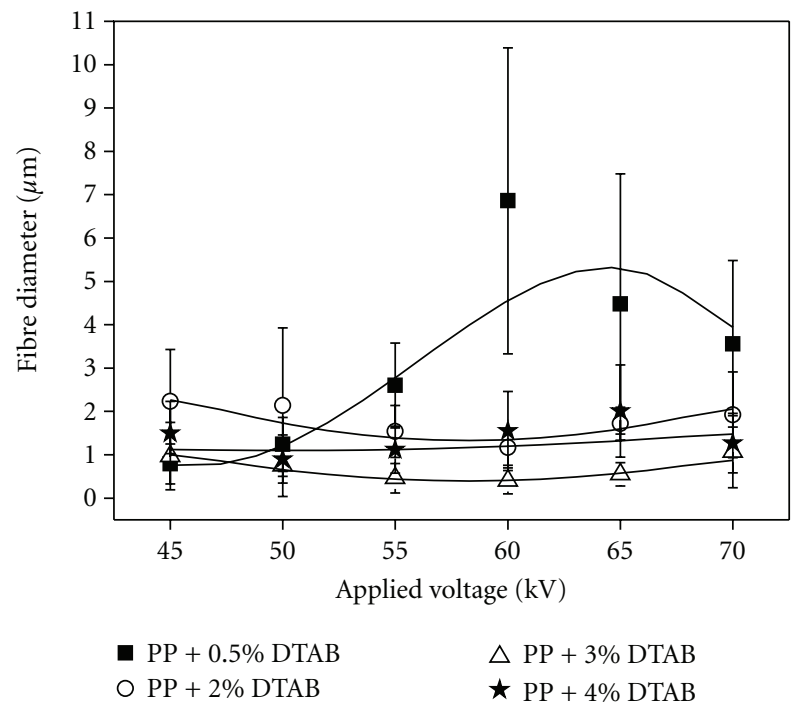

Figure 6: Relationship between fibre diameter and the applied voltage/DTAB concentration in $\mathrm{PP}(\mathrm{MF} 650 \mathrm{X}$, collecting distance $=$ $16 \mathrm{~cm})$.

was $0.5 \%$. The effect of DTAB on fibre diameter became obvious when the DTAB concentration was higher than $2 \%$, where nearly all fibres had a diameter less than $2 \mu \mathrm{m}$. The applied voltage also had very limited effect on the fibre diameter. The most significant decrease in fibre diameter occurred when the DTAB concentration was 3\%, because all fibres collected had a diameter less than $1 \mu \mathrm{m}$. Increasing the DTAB concentration further to $4 \%$ did not reduce the fibre diameter any more. It should be noted that $60 \mathrm{kV}$ was a critical voltage in most cases (Figure 7). At this voltage, the coarsest fibres $($ diameter $=6.86 \pm 3.53 \mu \mathrm{m}$ ) were prepared from a PP melt containing $0.5 \%$ DTAB, however the finest fibres $(0.40 \pm 0.29 \mu \mathrm{m})$ were also achieved from a PP melt containing $3 \%$ DTAB.
TABLE 1: FTIR peak assignments for polypropylene.

\begin{tabular}{lcc}
\hline Wave number $\left(\mathrm{cm}^{-1}\right)$ & Vibration type & Assignment \\
\hline 808 & Stretching & $\mathrm{C}-\mathrm{C}$ \\
840 & Rocking & $\mathrm{C}-\mathrm{H}$ \\
973 & Rocking & $\mathrm{CH}_{3}$ \\
& Stretching & $\mathrm{C}-\mathrm{C}$ \\
996 & Rocking & $\mathrm{CH}_{3}$ \\
& Stretching & $\mathrm{C}-\mathrm{C}$ \\
1166 & Wagging & $\mathrm{C}-\mathrm{H}$ \\
& Rocking & $\mathrm{CH}_{3}$ \\
1376 & Symmetrical bending & $\mathrm{CH}_{3}$ \\
1456 & Symmetrical bending & $\mathrm{CH}_{3}$ \\
2870 & Stretching & $\mathrm{CH}_{3}$ \\
2920 & Asymmetrical stretching & $\mathrm{CH}_{2}$ \\
2950 & Asymmetrical stretching & $\mathrm{CH}_{3}$ \\
\hline
\end{tabular}

The addition of DTAB to molten PP had a significant effect not only on the fibre diameter, but also on the electrospinning process. For the PP melt without DTAB, the spinning process could last for half an hour at most before the PP started degrading. However, when DTAB was added to the PP melt, the process was extended to at least an hour longer.

Figure 8 shows the FTIR spectra for PP and its blends containing $0.5 \%, 2 \%, 3 \%$ and $4 \%$ DTAB by weight. All spectra were very similar with each displaying the characteristic peaks of PP $[42,43]$, as listed in Table 1 . This suggested that adding DTAB into molten PP had a negligible effect on the chemical structure of PP.

It has been reported that DTAB is a cationic surfactant capable of reducing the entanglement of polymer chains [44, 45], which could be one of the reasons for the enhanced fibre thinning observed. A similar finding was also reported for di(2-ethylhexyl)phthalate (DOTP), which reduced the viscosity of molten poly(methyl methacrylate) (PMMA) to enable 


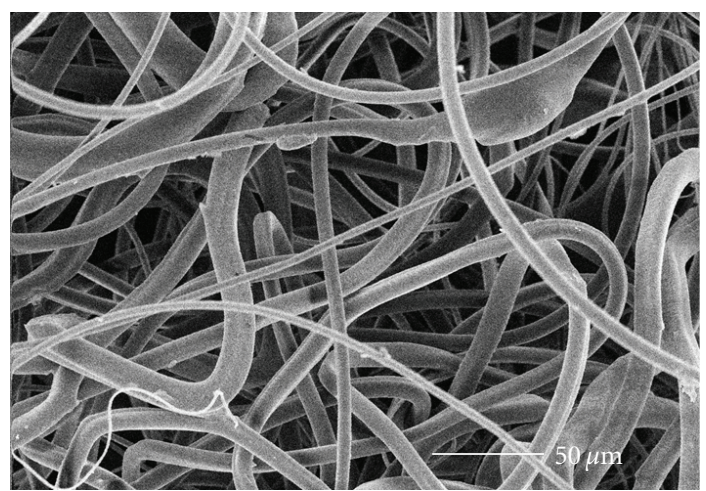

(a)

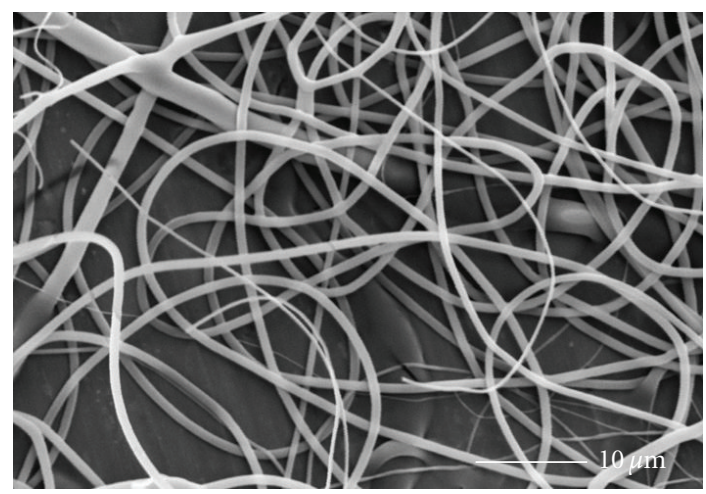

(c)

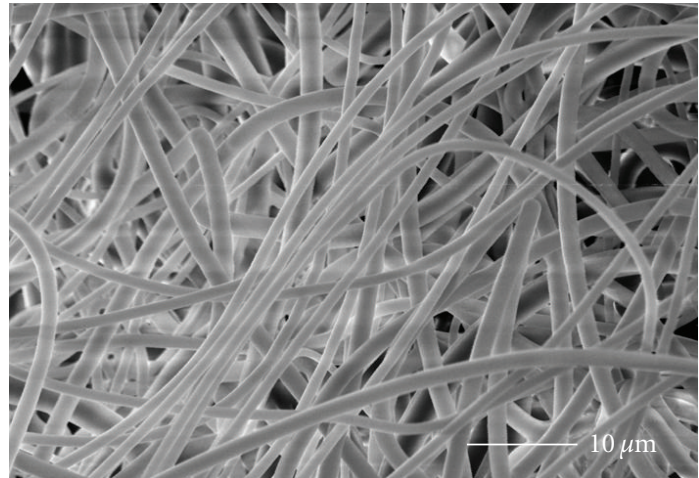

(b)

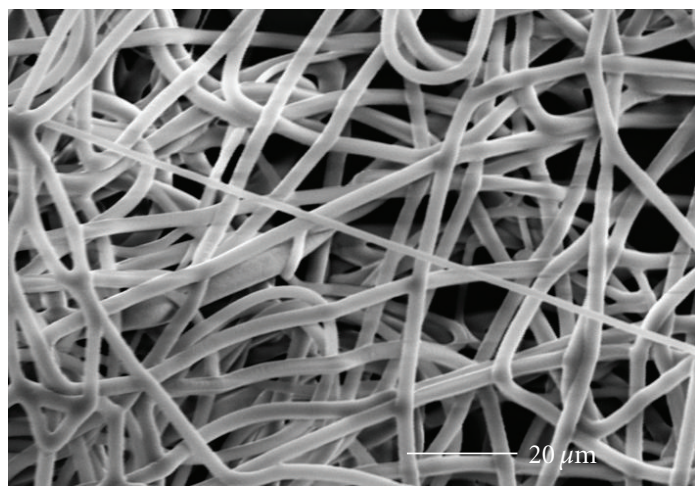

(d)

FIGURE 7: SEM images of the fibres electrospun from PP melt containing (a) 0.5\%, (b) 2\%, (c) 3\%, and (d) 4\% DTAB (applied voltage = $65 \mathrm{kV}$, collecting distance $=16 \mathrm{~cm}$ ).

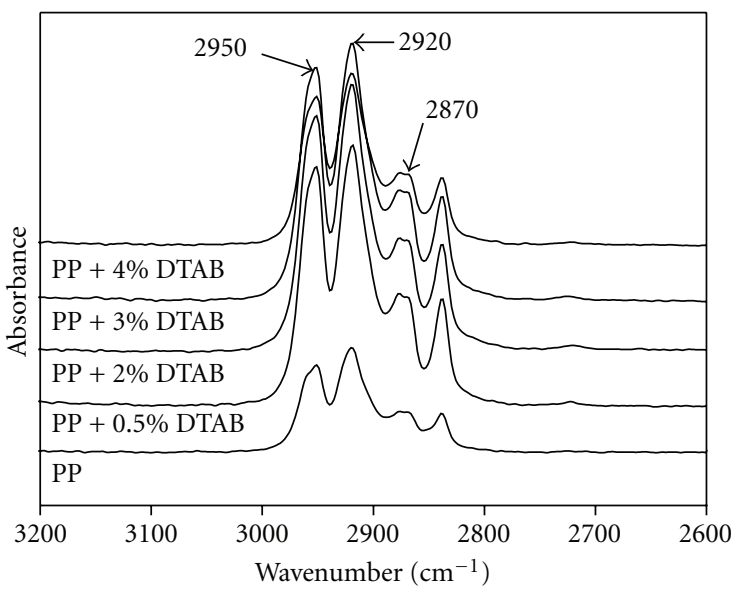

(a)

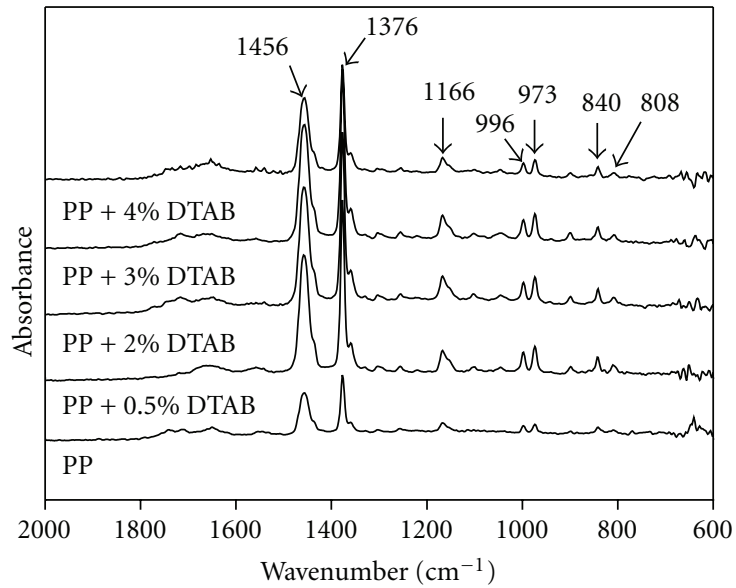

(b)

FIGURE 8: FTIR spectra of PP and PP/DTAB blends with different DTAB concentrations.

melt-electrospinning of fine PMMA fibres [30]. Another possible contribution of DTAB to the melt-electrospinning process was the presence of the extra electrical charges. It was reported that a small amount of DTAB in polystyrene solution improved the solution conductivity and reduced the fibre diameter, as well as increasing the fibre uniformity [38].

\section{Conclusions}

A novel needleless melt-electrospinning setup was developed to successfully produce PP nanofibres. By heating the melt bath and the disc separately, the melt temperature was well maintained. The metal material used for making the disc 
spinneret and the disc diameter had considerable effects on heat transfer and resulting fibre formation. Electric interference between the electric heaters and high voltage power source was avoided by charging the collector and electrically grounding the spinneret. The applied voltage was shown to have little effect on fibre diameter, however finer fibres were produced at a shorter collecting distance. When a cationic surfactant DTAB was added into the polymer melt, much finer fibres were electrospun. This novel setup has the potential to conquer the challenges in melt-electrospinning and provide an efficient, continuous, and highly productive fibre making technique.

\section{Authors' Contribution}

J. Fang and L. Zhang contributed equally to this paper.

\section{Acknowledgment}

This study was made possible by the generous support of LyondellBasell Australia Pty Ltd., which awarded the coveted Ian Heritage Scholarship to the second author.

\section{References}

[1] J. Doshi and D. H. Reneker, "Electrospinning process and applications of electrospun fibers," Journal of Electrostatics, vol. 35, no. 2-3, pp. 151-160, 1995.

[2] J. Fang, T. Lin, W. Tian, A. Sharma, and X. Wang, "Toughened electrospun nanofibers from crosslinked elastomer-thermoplastic blends," Journal of Applied Polymer Science, vol. 105, no. 4, pp. 2321-2326, 2007.

[3] A. Greiner and J. H. Wendorff, "Electrospinning: a fascinating method for the preparation of ultrathin fibers," Angewandte Chemie, vol. 46, no. 30, pp. 5670-5703, 2007.

[4] D. Li and Y. Xia, "Direct fabrication of composite and ceramic hollow nanofibers by electrospinning," Nano Letters, vol. 4, no. 5, pp. 933-938, 2004.

[5] T. Lin, H. Wang, H. Wang, and X. Wang, "Effects of polymer concentration and cationic surfactant on the morphology of electrospun polyacrylonitrile nanofibres," Journal of Materials Science and Technology, vol. 21, no. 1, pp. 9-12, 2005.

[6] T. Lin, H. Wang, and X. Wang, "Self-crimping bicomponent nanofibers electrospun from polyacrylonitrile and elastomeric polyurethane," Advanced Materials, vol. 17, no. 22, pp. 26992703, 2005.

[7] J. Fang, H. Niu, T. Lin, and X. Wang, "Applications of electrospun nanofibers," Chinese Science Bulletin, vol. 53, no. 15, pp. 2265-2286, 2008.

[8] H. Wang, J. Ding, B. Lee, X. Wang, and T. Lin, "Polypyrrolecoated electrospun nanofibre membranes for recovery of $\mathrm{Au}(\mathrm{III})$ from aqueous solution," Journal of Membrane Science, vol. 303, no. 1-2, pp. 119-125, 2007.

[9] H. Wang, J. Fang, T. Cheng et al., "One-step coating of fluorocontaining silica nanoparticles for universal generation of surface superhydrophobicity," Chemical Communications, no. 7, pp. 877-879, 2008.

[10] J. Fang, X. Wang, and T. Lin, "Electrical power generator from randomly oriented electrospun poly(vinylidene fluoride) nanofibre membranes," Journal of Materials Chemistry, vol. 21, no. 30, pp. 11088-11091, 2011.
[11] H. Niu, J. Zhang, Z. Xie, X. Wang, and T. Lin, "Preparation, structure and supercapacitance of bonded carbon nanofiber electrode materials," Carbon, vol. 49, no. 7, pp. 2380-2388, 2011.

[12] J. Lyons, C. Li, and F. Ko, "Melt-electrospinning part I: processing parameters and geometric properties," Polymer, vol. 45, no. 22, pp. 7597-7603, 2004.

[13] L. Larrondo and R. S. J. Manley, "lectrostatic fiber spinning from polymer metls-1. Experimental observations on fiber formation and properties," Journal of Polymer Science, vol. 19, no. 6, pp. 909-920, 1981.

[14] L. Larrondo and R. S. J. Manley, "Electrostatic fiber spinning from polymer metls-2. Examination of the flow field in an electrically driven jet," Journal of Polymer Science, vol. 19, no. 6, pp. 921-932, 1981.

[15] L. Larrondo and R. S. J. Manley, "Electrostatic fiber spinning from polymer metls-3. Electrostatic deformation of a pendant drop of polymer melt," Journal of Polymer Science, vol. 19, no. 6, pp. 933-940, 1981.

[16] P. D. Dalton, D. Grafahrend, K. Klinkhammer, D. Klee, and M. Möller, "Electrospinning of polymer melts: phenomenological observations," Polymer, vol. 48, no. 23, pp. 6823-6833, 2007.

[17] Y. Kadomae, Y. Maruyama, M. Sugimoto, T. Taniguchi, and K. Koyama, "Relation between tacticity and fiber diameter in melt-electrospinning of polypropylene," Fibers and Polymers, vol. 10, no. 3, pp. 275-279, 2009.

[18] E. Zhmayev, D. Cho, and Y. L. Joo, "Nanofibers from gasassisted polymer melt electrospinning," Polymer, vol. 51, no. 18, pp. 4140-4144, 2010.

[19] E. Zhmayev, D. Cho, and Y. L. Joo, "Modeling of melt electrospinning for semi-crystalline polymers," Polymer, vol. 51, no. 1, pp. 274-290, 2010.

[20] Y. Liu, X. Wang, H. Yan, C. Guan, and W. Yang, "Dissipative particle dynamics simulation on the fiber dropping process of melt electrospinning," Journal of Materials Science, vol. 46, no. 24, pp. 7877-7882, 2011.

[21] E. Zhmayev, D. Cho, and Y. Lak Joo, "Electrohydrodynamic quenching in polymer melt electrospinning," Physics of Fluids, vol. 23, no. 7, Article ID 073102, 2011.

[22] R. Deng, Y. Liu, Y. Ding, P. Xie, L. Luo, and W. Yang, "Melt electrospinning of low-density polyethylene having a low-melt flow index," Journal of Applied Polymer Science, vol. 114, no. 1, pp. 166-175, 2009.

[23] N. Ogata, G. Lu, T. Iwata, S. Yamaguchi, K. Nakane, and T. Ogihara, "Effects of ethylene content of poly(ethylene-covinyl alcohol) on diameter of fibers produced by melt-electrospinning," Journal of Applied Polymer Science, vol. 104, no. 2, pp. 1368-1375, 2007.

[24] N. Ogata, N. Shimada, S. Yamaguchi, K. Nakane, and T. Ogihara, "Melt-electrospinning of poly(ethylene terephthalate) and polyalirate," Journal of Applied Polymer Science, vol. 105, no. 3, pp. 1127-1132, 2007.

[25] N. Ogata, S. Yamaguchi, N. Shimada et al., "Poly(lactide) nanofibers produced by a melt-electrospinning system with a laser melting device," Journal of Applied Polymer Science, vol. 104, no. 3, pp. 1640-1645, 2007.

[26] P. D. Dalton, J. Lleixà Calvet, A. Mourran, D. Klee, and M. Möller, "Melt electrospinning of poly-(ethylene glycol-blockepsilon-caprolactone)," Biotechnology Journal, vol. 1, no. 9, pp. 998-1006, 2006.

[27] Y. Liu, R. Deng, M. Hao, H. Yan, and W. Yang, "Orthogonal design study on factors effecting on fibers diameter of melt electrospinning," Polymer Engineering and Science, vol. 50, no. 10, pp. 2074-2078, 2010. 
[28] S. Tian, N. Ogata, N. Shimada, K. Nakane, T. Ogihara, and $\mathrm{M}$. Yu, "Melt electrospinning from poly(L-lactide) rods coated with poly(ethylene-co-vinyl alcohol)," Journal of Applied Polymer Science, vol. 113, no. 2, pp. 1282-1288, 2009.

[29] N. Detta, T. D. Brown, F. K. Edin et al., "Melt electrospinning of polycaprolactone and its blends with poly(ethylene glycol)," Polymer International, vol. 59, no. 11, pp. 1558-1562, 2010.

[30] X. F. Wang and Z. M. Huang, "Melt-electrospinning of PMMA," Chinese Journal of Polymer Science, vol. 28, no. 1, pp. 45-53, 2010.

[31] D. W. Hutmacher and P. D. Dalton, "Melt electrospinning," Chemistry, vol. 6, no. 1, pp. 44-56, 2011.

[32] S. Lee and S. K. Obendorf, "Developing protective textile materials as barriers to liquid penetration using melt-electrospinning," Journal of Applied Polymer Science, vol. 102, no. 4, pp. 3430-3437, 2006.

[33] H. Zhou, T. B. Green, and Y. L. Joo, "The thermal effects on electrospinning of polylactic acid melts," Polymer, vol. 47, no. 21, pp. 7497-7505, 2006.

[34] S. Chung, N. P. Ingle, G. A. Montero, S. H. Kim, and M. W. King, "Bioresorbable elastomeric vascular tissue engineering scaffolds via melt spinning and electrospinning," Acta Biomaterialia, vol. 6, no. 6, pp. 1958-1967, 2010.

[35] A. Karchin, F. I. Simonovsky, B. D. Ratner, and J. E. Sanders, "Melt electrospinning of biodegradable polyurethane scaffolds," Acta Biomaterialia, vol. 7, no. 9, pp. 3277-3284, 2011.

[36] K. Watanabe, B. S. Kim, and I. S. Kim, "Development of polypropylene nanofiber production system," Polymer Reviews, vol. 51, no. 3, pp. 288-308, 2011.

[37] H. Niu, T. Lin, and X. Wang, "Needleless electrospinning. I. A comparison of cylinder and disk nozzles," Journal of Applied Polymer Science, vol. 114, no. 6, pp. 3524-3530, 2009.

[38] T. Lin, H. Wang, H. Wang, and X. Wang, "The charge effect of cationic surfactants on the elimination of fibre beads in the electrospinning of polystyrene," Nanotechnology, vol. 15, no. 9, pp. 1375-1381, 2004.

[39] W. Janna, Engineering Heat Transfer, CRC Press, Boca Raton, Fla, USA, 2nd edition, 2000.

[40] V. E. Kalayci, P. K. Patra, Y. K. Kim, S. C. Ugbolue, and S. B. Warner, "Charge consequences in electrospun polyacrylonitrile (PAN) nanofibers,” Polymer, vol. 46, no. 18, pp. 71917200, 2005.

[41] T. Lin, J. Fang, H. Wang, T. Cheng, and X. Wang, "Using chitosan as a thickener for electrospinning dilute PVA solutions to improve fibre uniformity," Nanotechnology, vol. 17, no. 15, article 017, pp. 3718-3723, 2006.

[42] S. A. Hedrick and S. S. C. Chuang, "Temperature programmed decomposition of polypropylene: in situ FTIR coupled with mass spectroscopy study," Thermochimica Acta, vol. 315, no. 2, pp. 159-168, 1998.

[43] H. M. Abdel-Hamid, "Effect of electron beam irradiation on polypropylene films-dielectric and FT-IR studies," Solid-State Electronics, vol. 49, no. 7, pp. 1163-1167, 2005.

[44] J. A. Johnson, M. J. Barbato, S. R. Hopkins, and M. J. O’Malley, "Dispersion and film properties of carbon nanofiber pigmented conductive coatings," Progress in Organic Coatings, vol. 47, no. 3-4, pp. 198-206, 2003.

[45] D. Myers, Surfactant Science and Technology, John Wiley \& Sons, Hoboken, NJ, USA, 3rd edition, 2006. 

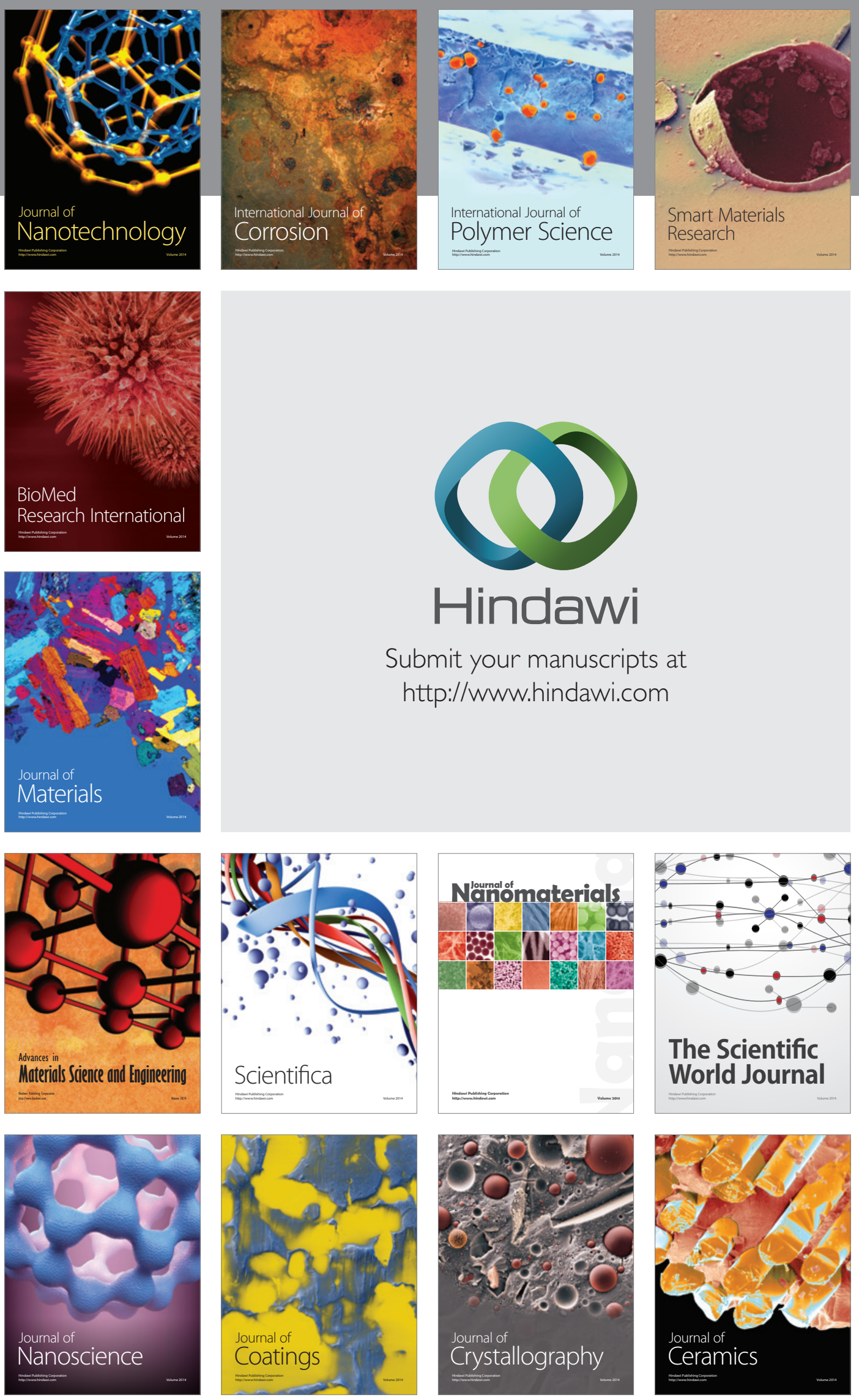

The Scientific World Journal

Submit your manuscripts at

http://www.hindawi.com

\section{World Journal}

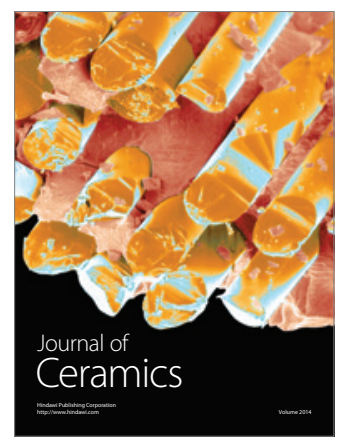

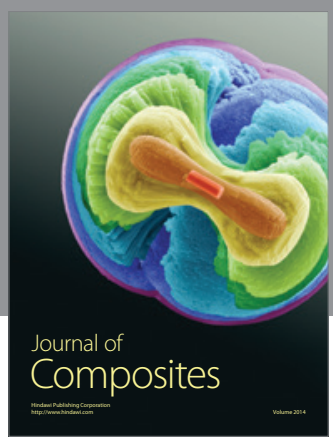
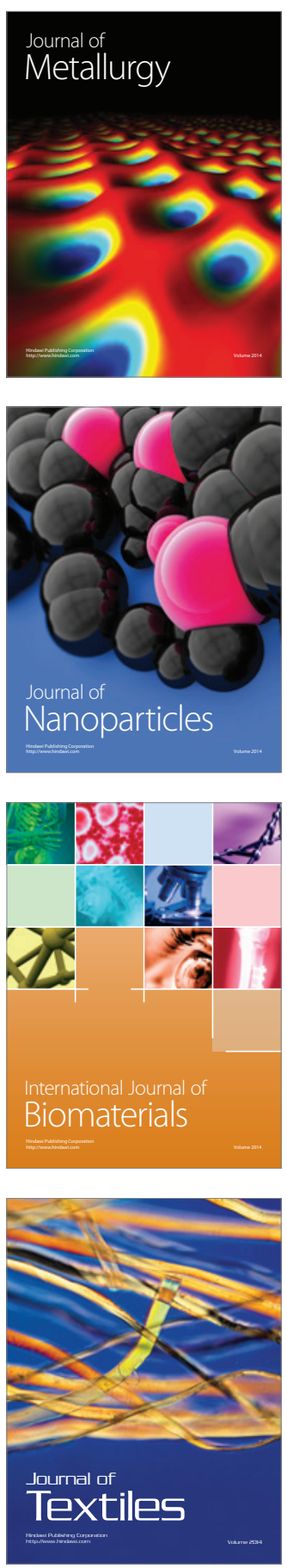